\title{
SYNTHESIS AND EVALUATION OF ANTIDIABETIC PROPERTIES OF A ZINC MIXED LIGAND COMPLEX IN HIGH-FAT DIET - LOW-DOSE STREPTOZOTOCIN-INDUCED DIABETIC RATS
}

\author{
MURUGANANTHAM KOOTHAPPAN ${ }^{1}$, ROSHANA DEVI VELLAI ${ }^{1}$, IYYAM PILLAI SUBRAMANIAN ${ }^{2}$, \\ SUBRAMANIAN SORIMUTHU PILLAI ${ }^{1 *}$
}

${ }^{1}$ Department of Biochemistry, University of Madras, Guindy Campus, Chennai - 600 025, Tamil Nadu, India. ${ }^{2}$ Department of Chemistry, Pachaiyappa's College, Chennai - 600 030, Tamil Nadu, India. Email: subbus2020@yahoo.co.in

Received: 22 January 2018, Revised and Accepted: 19 February 2018

ABSTRACT

Objective: Due to the multifactorial and multisystemic nature of diabetes mellitus (DM), it is often treated with a combination of therapeutic agents. Earlier, we have synthesized and characterized several organozinc complexes and evaluated their safety and antidiabetic properties in experimental DM. In the present study, a new zinc mixed ligand (metformin-3-hydroxyflavone) was synthesized and characterized by various spectral studies and its antidiabetic properties were evaluated in high-fat diet (HFD) fed - low-dose streptozotocin (STZ)-induced Type 2 D (T2D) in rats.

Methods: The zinc mixed ligand complex was characterized by spectral studies. The toxicity and dosage fixation studies were carried out as per OECD guidelines 423. HFD fed low-dose STZ-induced T2DM in rats was used as the experimental model. The hypoglycemic efficacy of the complex was evaluated through oral glucose tolerance test, homeostasis model assessment of insulin resistance (IR), QUICK I and by determining the status of important biochemical parameters. The activities of marker enzymes such as aspartate aminotransferase, alanine aminotransferase, and alkaline phosphatase were assayed. Metformin was used as a standard drug.

Results: The spectral data evidenced the synthesis of a new zinc mixed ligand complex. The biochemical studies evidenced that the oral administration of the complex at a concentration of $10 \mathrm{mg} / \mathrm{kg} \mathrm{b.w/rat/day} \mathrm{for} 30$ days to diabetic rats significantly improved the glucose homeostasis which was comparable to metformin treatment $(50 \mathrm{mg} / \mathrm{kg} \mathrm{b.w})$.

Conclusion: The zinc mixed complex possesses significant antidiabetic properties in ameliorating IR and stimulatory properties.

Keywords: Diabetes, Zinc complexes, Metformin-3-hydroxyflavone, Spectral studies, Antidiabetic properties.

(C) 2018 The Authors. Published by Innovare Academic Sciences Pvt Ltd. This is an open access article under the CC BY license (http://creativecommons. org/licenses/by/4. 0/) DOI: http://dx.doi.org/10.22159/ajpcr.2018.v11i6.24870

\section{INTRODUCTION}

Diabetes mellitus (DM) is a chronic metabolic disorder arises due to an absolute lack of insulin secretion (Type 1 DM [T1DM]) or its action coupled with insufficient levels (T2DM) [1]. DM is a major epidemic of this century as its prevalence is increasing alarmingly worldwide [2]. T2DM accounts for more than $90 \%$ of the entire diabetic population and its incidence are projected to rise 642 million by the year 2025 [3]. Several drugs such as biguanides, sulfonylureas, meglitinides, thiazolidines, $\alpha$-glucosidase inhibitors, bile acid sequestrants, sodiumglucose cotransporter-2 inhibitors, glucagon-like peptide-1 (GLP-1) receptor agonists, and insulin are currently used either as monotherapy or combinatorial strategy. However, maintenance of normoglycemia remains a major task in the treatment of patients with T2DM [4]. Accordingly, instead of a one-size-fit-all approach, personalization is necessary, balancing the benefit of glycemic control with its potential risk factors taking into consideration of various etiological factors such as the patient's age, blood pressure control, lipid management, and comorbidities that are frequently encountered in diabetic patients [5].

Phytochemicals are ecologically derived plant secondary metabolites which protect them against environmental stress such as ultraviolet radiation, pollution, high temperature, extreme cold, drought, flood, tissue damage, and microbial attacks [6]. Interestingly, these secondary metabolites are known to play a pivotal role in alleviating the primary and secondary complications of dreadful human diseases such as cancer, diabetes, and atherosclerosis [7]. Among the various phyto ingredients, flavonoids are known for their wide range of pharmacological as well as beneficial effects in the maintenance of human health care especially in quenching oxidative stress, a major contributory factor for the progression of secondary complications [8]. Among flavonoids, flavones are known to chelate the metal ions with great affinity due to the presence of $\alpha$-hydroxycarbonyl group and their ability to scavenge excessive free radicals [9]

Metformin originally isolated from Galega officinalis, a plant traditionally used in the treatment of diabetes, remains the optimum drug for the treatment of T2DM due to its proven safety record, weight neutrality and possible benefits on cardiovascular outcomes in addition to its low cost $[10,11]$. Although metformin is efficacious in lowering blood glucose as well as glycosylated hemoglobin (HbA1c) levels, many patients with T2DM are not adequately controlled when metformin is prescribed as monotherapy [12]. Further, the bioavailability of metformin is dose-dependent and its treatment at high doses was associated with metabolic acidosis characterized by increased serum lactate and betahydroxybutyric acid levels and decreased serum bicarbonate and urine $\mathrm{pH}$. Given the superior efficacy of metformin when compared to other currently available antidiabetic agents, new pharmaceuticals will likely be developed as cotherapies with metformin.

In the $21^{\text {st }}$ century, a new class of metallopharmaceutical compounds containing zinc ions is expected to treat both types of DM by making use of its unique pharmacological properties [13]. Ever since in 1980, Coulston and Dandona reported the insulin mimetic activity of zinc ions, several research groups developed insulin mimetic zinc complexes with various coordination modes around zinc (II) ion and evaluated its glucose normalizing effect [14]. In the recent past, we have synthesized several new zinc complexes such as zinc-flavonol [15], zinc-morin [16], zinc-silibinin [17], zinc-diosmin [18] and evaluated for its toxicity as 
well as pharmacological properties in high-fat diet (HFD) fed - low-dose streptozotocin (STZ)-induced experimental T2D in rats. In the light of knowledge and expertise gained, in the present study an attempt has been made to synthesize a new metformin-zinc-flavonol complex and biochemically evaluated its toxicity as well as antidiabetic properties.

\section{METHODS}

\section{Chemicals}

Zinc acetate $\left[\mathrm{Zn} \quad\left(\mathrm{O}_{2} \mathrm{CCH}_{3}\right)_{2}\left(\mathrm{H}_{2} \mathrm{O}\right)_{2}\right]$, 3-hydroxyflavone $\left(\mathrm{C}_{15} \mathrm{H}_{10} \mathrm{O}_{3}\right)$, metformin and STZ were purchased from Sigma-Aldrich, St. Louis, USA. For the assay of insulin and C-peptide, ultra-sensitive ELISA kit was purchased from Crystal Chem Inc. Life Technologies, India. The other reagents procured for conducting present study were of analytical grade.

\section{Analytical instruments}

Infrared (IR) spectral studies were performed in the solid state as pressed $\mathrm{KBr}$ pellets using a Perkin-Elmer Fourier transform IR spectrophotometer in the range of $400-4000 / \mathrm{cm}$. The fluorescence of the complex was recorded using a Perkin-Elmer spectrofluorimeter. The mass spectrum of the complex was obtained using Jeol Gcmate. The ${ }^{1} \mathrm{H}$ nuclear magnetic resonance (NMR) and ${ }^{13} \mathrm{C}$ NMR were obtained at $300 \mathrm{MHz}$ and $500 \mathrm{MHz}$, respectively, using a Bruker AM-500 instrument. All the spectral data obtained were recorded without any modification for instrumental uniqueness.

Synthesis of novel Schiff base ligand using metformin and 3-hydroxyflavone

Briefly, for the synthesis of Schiff base, 3-Hydroxyflavone $(0.005 \mathrm{~mol}$, $1.2 \mathrm{~g}$ ) is dissolved in $25 \mathrm{ml}$ of methanol and stirred continuously in hot condition till the formation of a clear solution is achieved. To the resultant solution, metformin $(0.005 \mathrm{~mol}, 0.6458 \mathrm{~g})$ in methanol $(25 \mathrm{ml})$ is added in a dropwise manner and refluxed with constant stirring over a water bath for about $6 \mathrm{~h}$ or till the color changes completely. The colored product (L1) obtained was washed carefully with water as well as methanol, dried under vacuum, and recrystallized.

\section{Synthesis of zinc complex using Schiff base ligand L}

For the synthesis of zinc complex using Schiff base ligand, zinc acetate $(0.02 \mathrm{~mol}, 0.37 \mathrm{~g})$ in $10 \mathrm{ml}$ of methanol was added in a dropwise manner to the methanolic solution of the Schiff base $(0.02 \mathrm{~mol}, 0.7 \mathrm{~g})$ and the mixture was refluxed on a water bath for $2 \mathrm{~h}$ with constant stirring to get a colored solution. Stirring was further continued for $1 \mathrm{~h}$ at room temperature. The complex obtained was filtered, washed with water as well as hot methanol and dried under vacuum.

\section{Experimental animals}

Male Albino rats of Wistar strain weighing around 160-180 g were purchased from the Tamil Nadu Veterinary and Animal Sciences University, Chennai, and were housed under standard animal husbandry conditions. The rats were acclimatized for 2 weeks before initiating the experiments. Animal experiments were performed according to ethical norms approved by the Ministry of Social Justices and Empowerment, Government of India, and Institutional Animal Ethics Committee guidelines (IAEC N0:03/10/12). Maximum efforts were taken to minimize the sufferings of the animals during the entire course of the study, and no mortality was observed during the experimental period.

\section{Induction of experimental diabetes}

The experimental rats were designated as two dietary regimens either by feeding normal pellet diet (NPD) or HFD for 2 weeks. The composition of the HFD include powdered NPD- $365 \mathrm{~g} / \mathrm{kg}$, lard- $310 \mathrm{~g} / \mathrm{kg}$, casein- $250 \mathrm{~g} / \mathrm{kg}$, cholesterol- $10 \mathrm{~g} / \mathrm{kg}$, Vitamin and mineral mix- $60 \mathrm{~g} / \mathrm{kg}$, DL-methionine- $3 \mathrm{~g} / \mathrm{kg}$, yeast powder- $1 \mathrm{~g} / \mathrm{kg}$, and $\mathrm{NaCl}-1 \mathrm{~g} / \mathrm{kg}$. After 2 weeks of dietary manipulation, Groups 2-4 rats were injected with a single dose of STZ (35 mg/kg b.w/rat) in ice cold citrate buffer (pH 4.5, $0.1 \mathrm{~mol} / \mathrm{L}$ ) intraperitoneally. However, the control group of rats was fed with NPD and injected intraperitoneally with the same volume of citrate buffer [19]. Rats having the fasting blood glucose levels $\geq 250 \mathrm{mg} /$ $\mathrm{dl}$ on the $3^{\text {rd }}$ day after STZ injection were considered as diabetic and subjected to further studies.

\section{Acute toxicity and dosage fixation studies}

For acute toxicity studies, graded doses of zinc-metformin-3 hydroxyflavone complex in aqueous suspension were administered orally to control animals. The rats were closely monitored for any change in food and fluid intake, psychomotor activities, body weight, changes in skin, fur, eyes, salivation, diarrhea, and lethargy. Vital organs were subjected to macroscopic observations. Similarly, the dosage fixation studies were also conducted using graded doses of the complex $(5,10,20$, and $50 \mathrm{mg} / \mathrm{kg} \mathrm{b.w} / \mathrm{rat} /$ day $)$ for 30 days to fix the dose-dependent hypoglycemic effect in HFD fed low-dose STZinduced experimental T2D rats based on the fasting blood glucose levels.

\section{Experimental protocol}

The rats were divided into four groups and each comprising of six animals:

- Group 1: Control rats.

- Group 2: HFD fed-STZ induced experimental diabetic rats.

- Group 3: HFD-STZ induced diabetic rats orally treated with zincmetformin-3-hydroxyflavone complex (10 mg/kg b.w/rat/day) for 30 days.

- Group 4: HFD-STZ induced diabetic rats orally treated with metformin (50 mg/kg b.w/rat/day) for 30 days.

\section{Oral glucose tolerance test (OGTT)}

On the day before sacrifice, OGTT was performed in all the groups of rats. Blood samples were collected from the lateral tail vein of rats deprived of food overnight. Successive blood samples were taken at 0 , $30,60,90$, and $120 \mathrm{~min}$ following the oral administration of $2 \mathrm{mg} / \mathrm{kg}$ b.w of glucose solution.

\section{Homeostasis model assessment of insulin resistance (HOMA-IR) and QUICKI}

The abnormalities in the synthesis and secretion of insulin cannot be assessed by a single estimation of insulin or blood glucose levels; the resistance to insulin action was determined by HOMA-IR. The extent of IR/sensitivity was assessed by QUICKI.

Quantitative insulin check index as follows:

HOMA - IR $=\frac{\text { Fasting insulin level } \times \text { Fasting blood glucose }}{405}$

QUICKI $=1 /(\log ($ fasting insulin $\mu \mathrm{U} / \mathrm{mL})+\log$ (fasting glucose $\mathrm{mg} / \mathrm{dL}$ )

\section{Biochemical analysis}

At the end of 30 days of treatment, rats were fasted overnight, anesthetized and sacrificed by cervical decapitation. The biochemical parameters were assayed using standard protocols. Blood was collected with and without anticoagulants for the separation of plasma and serum, respectively. The levels of fasting blood glucose, hemoglobin, and $\mathrm{HbA1c}$ were estimated. Ultrasensitive ELISA kits were used for the assay of insulin and C-peptide. The levels of plasma protein, blood urea, serum creatinine, and serum uric acid were estimated. The activities of aspartate aminotransferase (AST), alanine aminotransferase (ALT), and alkaline phosphatase (ALP) in serum were assayed. Urine sugar was detected using urine strips.

\section{Statistical analysis}

The results were expressed as a mean \pm standard error of the mean of six rats per group, and the statistical significance was evaluated by "one-way analysis of variance" (ANOVA) using the SPSS (version 16) program followed by least significance test. $\mathrm{p}<0.05$ was considered to indicate statistical significance. 


\section{RESULTS}

Synthesis of mixed ligand complex

Scheme 1 represents the synthesis of a Schiff base ligand (L) from the coordination between 3-hydroxyflavone and metformin by a molar ratio method and the product obtained was yellow in color. Similarly, the new zinc mixed ligand complex synthesized using Schiff base ligand (L), and zinc acetate was pale yellow in color, and the yield was about $96 \%$ (Scheme 2). The molecular formula of the proposed zinc mixed ligand complex is $\mathrm{C}_{38} \mathrm{H}_{35} \mathrm{~N}_{10} \mathrm{O}_{4} \mathrm{Zn}$.

\section{Spectral characterization}

The IR spectral data of metformin and 3-hydroxyflavone were presented as Figs. 1 and 2, respectively. The IR spectrum of Schiff base and its zinc

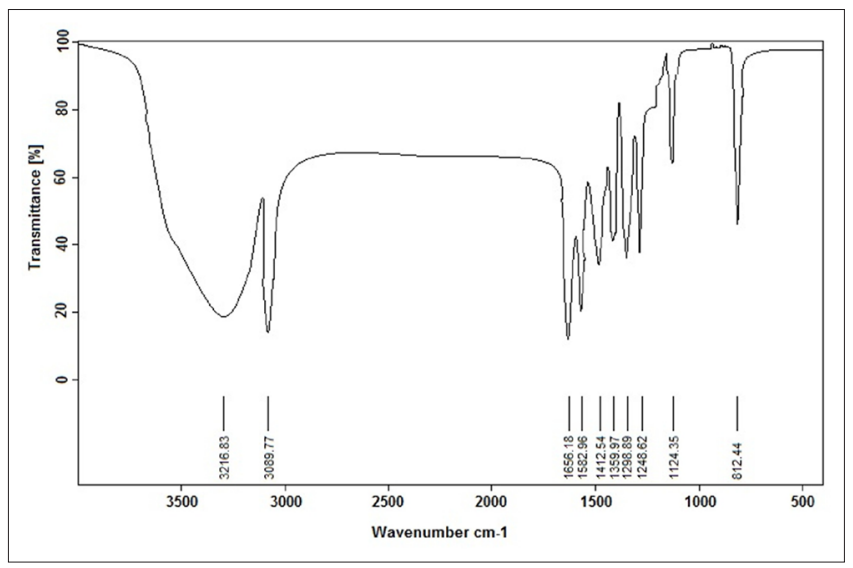

Fig. 1: The infrared spectrum 3-hydroxyflavone

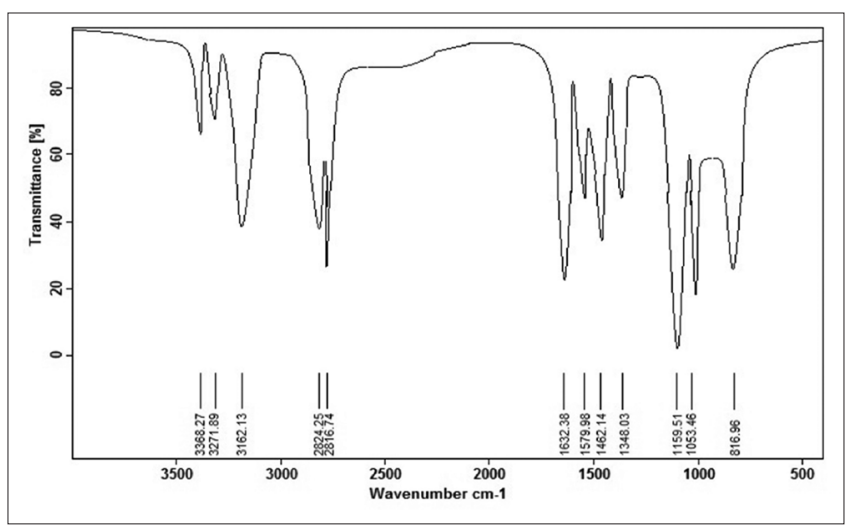

Fig. 2: The infrared spectrum of metformin mixed ligand complex was shown in Figs. 3 and 4 [IR $\left.\left(\mathrm{KBr}, \mathrm{vcm}{ }^{-1}\right)\right]$, respectively.

Mass spectrum analysis of Schiff base ligand and mixed ligand complex were shown in Figs. 5 and 6, respectively. Proton NMR spectrum of metformin and 3-hydroxyflavone were depicted as Figs. 7 and 8, respectively.

The proton NMR of Schiff base ligand and mixed ligand complex were shown in Figs. 9 and 10, respectively. ${ }^{13} \mathrm{C}$ NMR spectrum of metformin and 3-hydroxyflavone were shown in Figs. 11 and 12, respectively. The ${ }^{13} \mathrm{C}$ NMR spectrum of Schiff base ligand and mixed ligand complex were shown in Figs. 13 and 14, respectively.

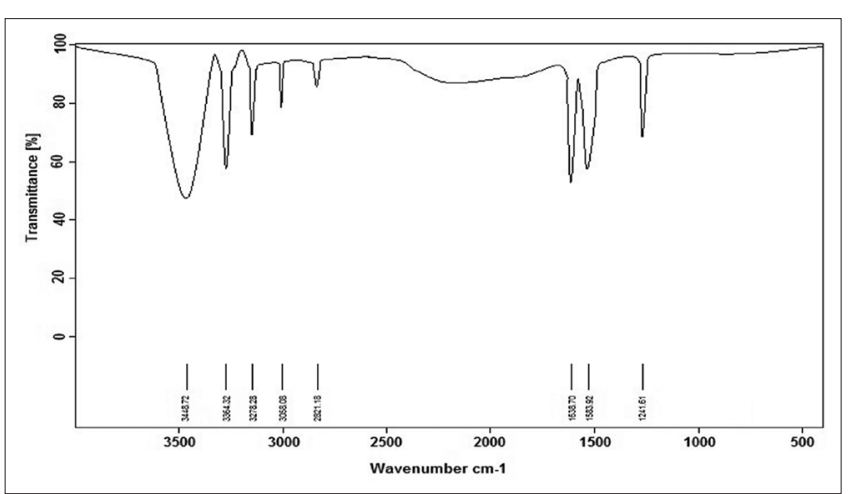

Fig. 3: The infrared spectrum of 3-hydroxyflavone and metformin ligand

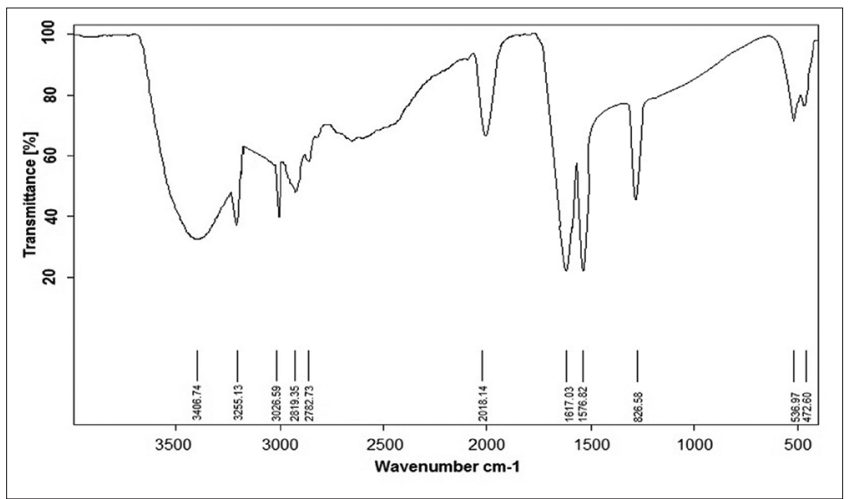

Fig. 4: The infrared spectrum of Zn-Schiff base ligand

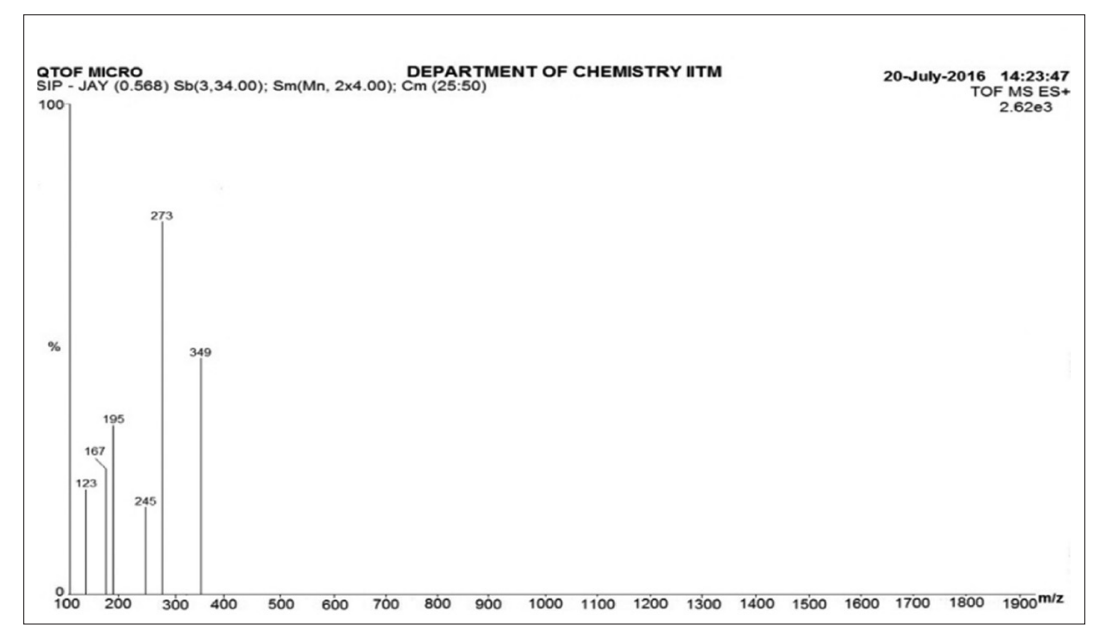

Fig. 5: The mass spectrum 3-hydroxyflavone and metformin ligand 


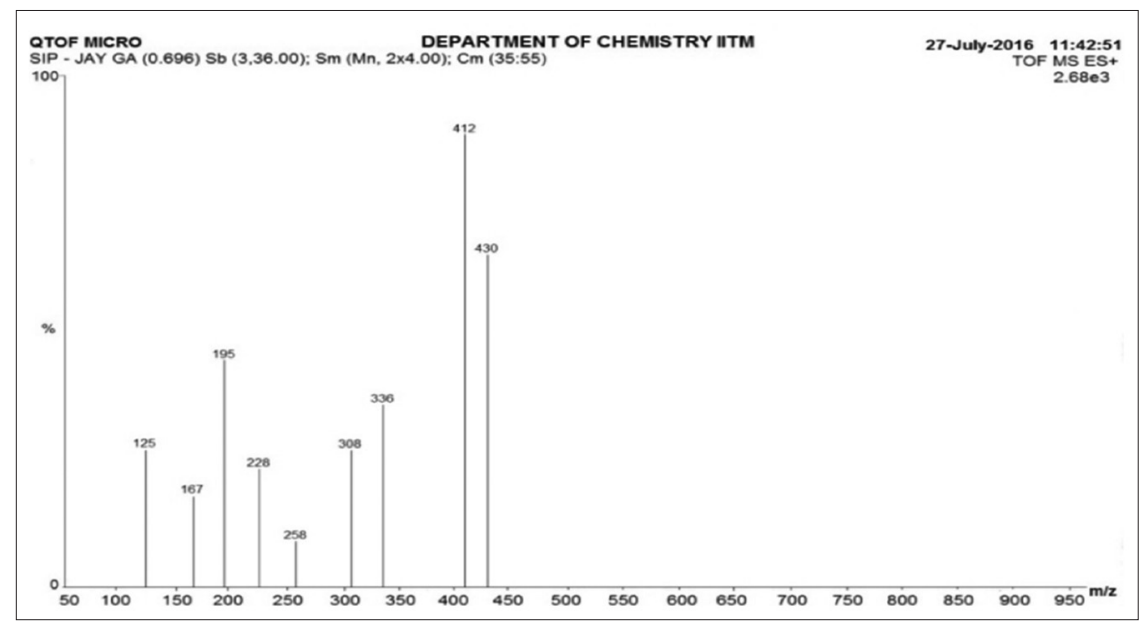

Fig. 6: The mass spectrum of Zn-Schiff base ligand

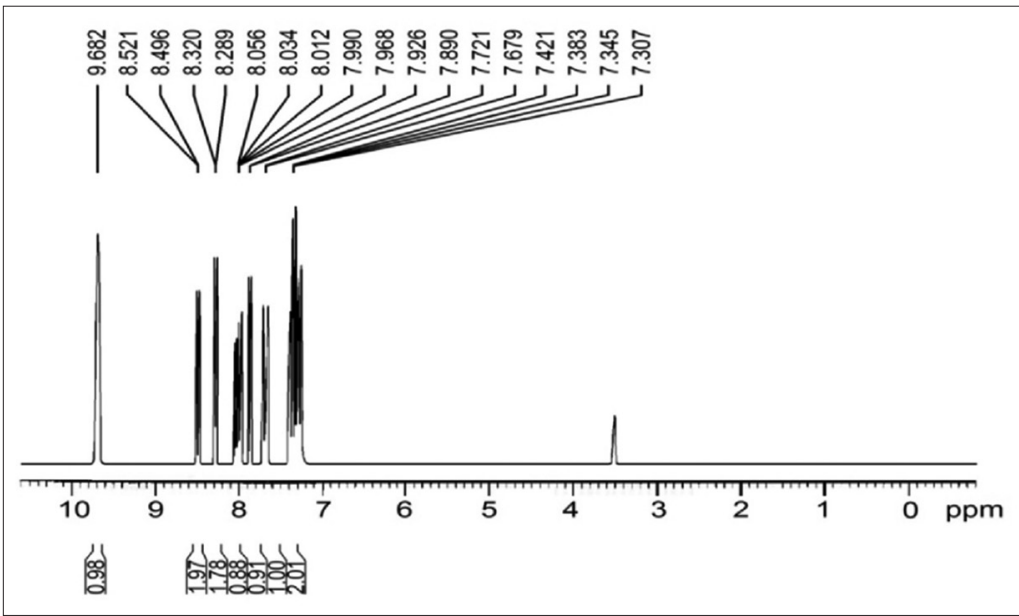

Fig. 7: The proton ${ }^{1} \mathrm{H}$ nuclear magnetic resonance of 3-hydroxyflavones

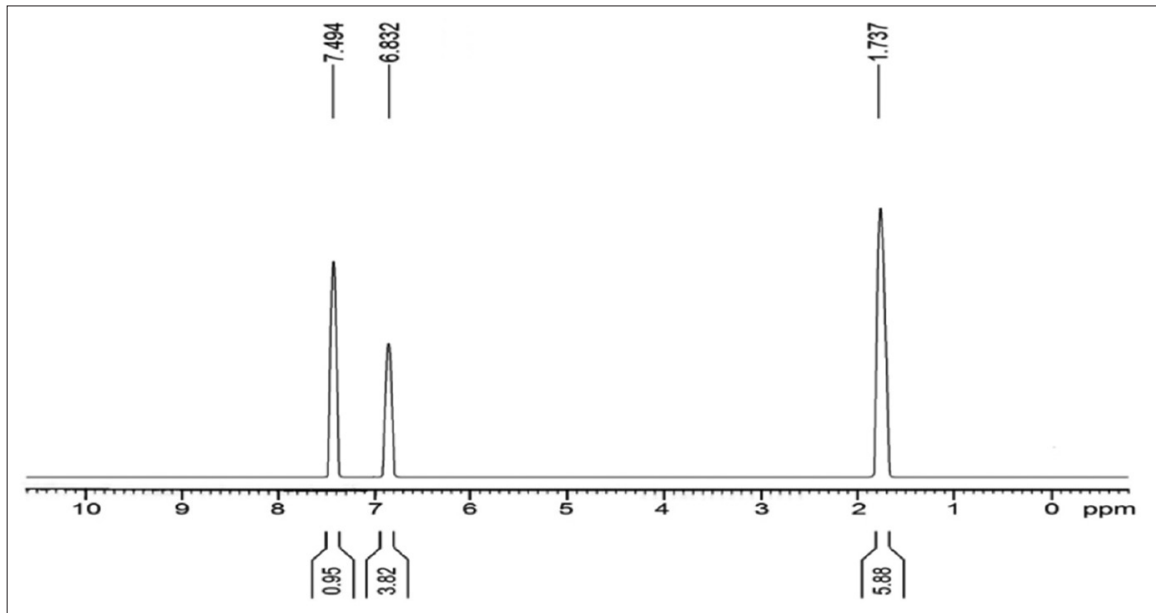

Fig. 8: The proton ${ }^{1} \mathrm{H}$ nuclear magnetic resonance of metformin

\section{Biochemical studies}

The effect of oral administration of the mixed ligand complex on glucose tolerance in diabetic rats after oral glucose load is graphically represented in Fig. 15. In the diabetic group of rats, the blood glucose levels reached a maximum peak at $60 \mathrm{~min}$ and did not return to the basal level even at the end of $120 \mathrm{~min}$. Oral administration of the mixed ligand - zinc complex to diabetic rats showed a significant decrease in blood glucose concentration at fasting when compared with diabetic rats. Although the blood glucose levels reached a maximum peak value at $60 \mathrm{~min}$ after oral glucose load in the complex treated diabetic rats, the levels were significantly lower than those observed in the diabetic group of rats, and the peak was reversed to the physiological level in the next $60 \mathrm{~min}$ and these observations were comparable with metformin. 


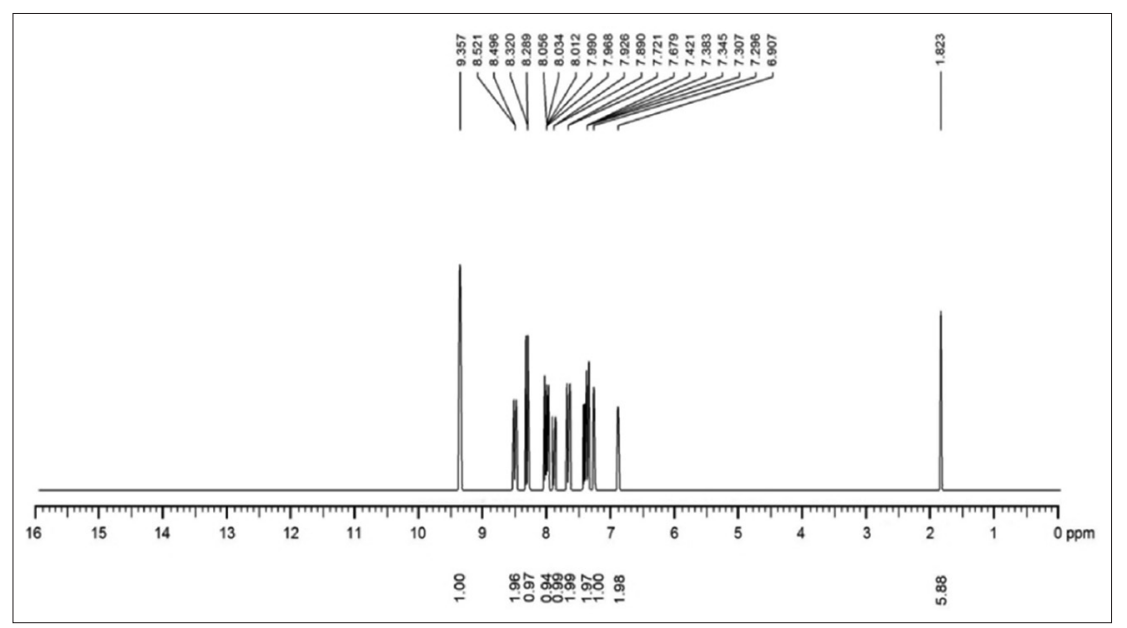

Fig. 9: The proton ${ }^{1} \mathrm{H}$ nuclear magnetic resonance of 3-hydroxyflavone and metformin ligand

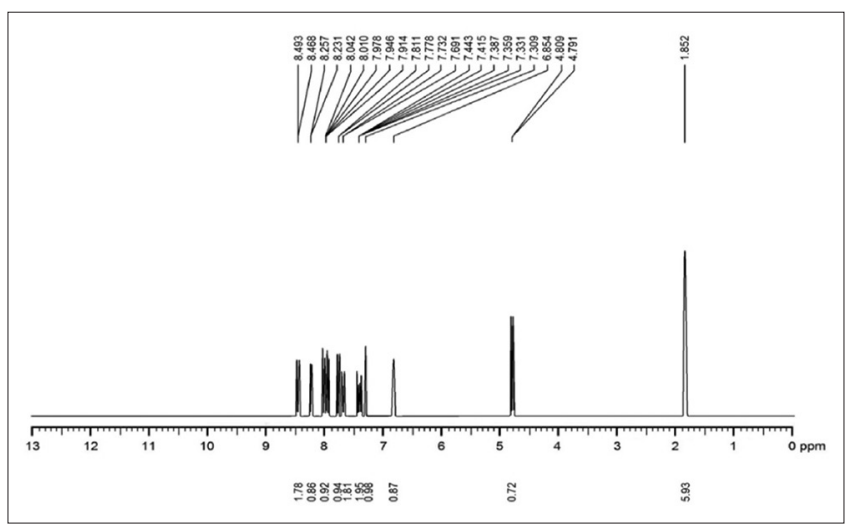

Fig. 10: The proton ${ }^{1} \mathrm{H}$ nuclear magnetic resonance of $\mathrm{Zn}$-Schiff base ligand

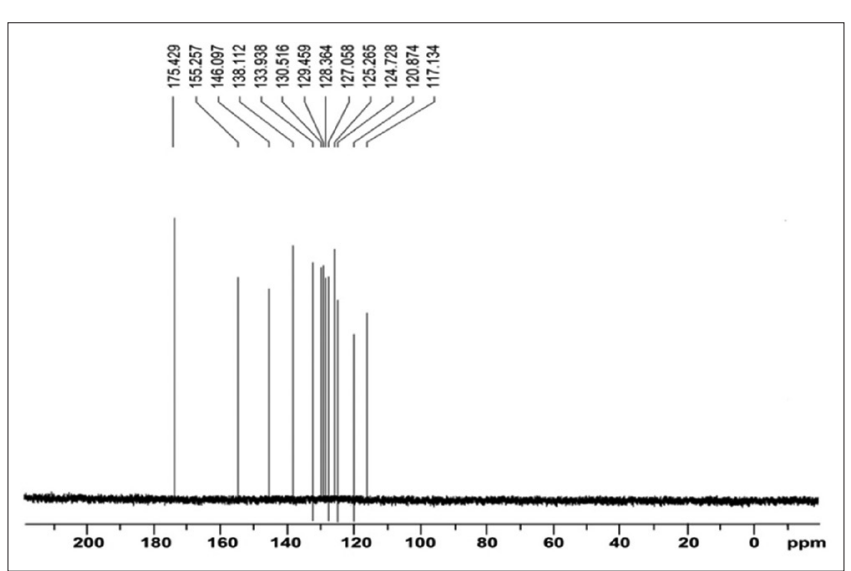

Fig. 11: The proton ${ }^{13} \mathrm{C}$ nuclear magnetic resonance of 3-hydroxyflavones

HOMA-IR and QUICKI values of control and experimental groups of rats were depicted in Figs. 16 and 17, respectively. The diabetic rats showed a significant elevation in HOMA-IR and QUICKI values that were decreased significantly on treatment with oral administration of mixed ligand zinc complex as well as metformin.

Table 1 depicts the levels of fasting blood glucose, hemoglobin, HbA1c, plasma insulin, C-peptide and the inference for the presence of urine sugar in control as well as experimental groups of rats. Diabetic group of rats showed significantly elevated levels of fasting glucose and $\mathrm{HbA1} \mathrm{c}$ and a concomitant

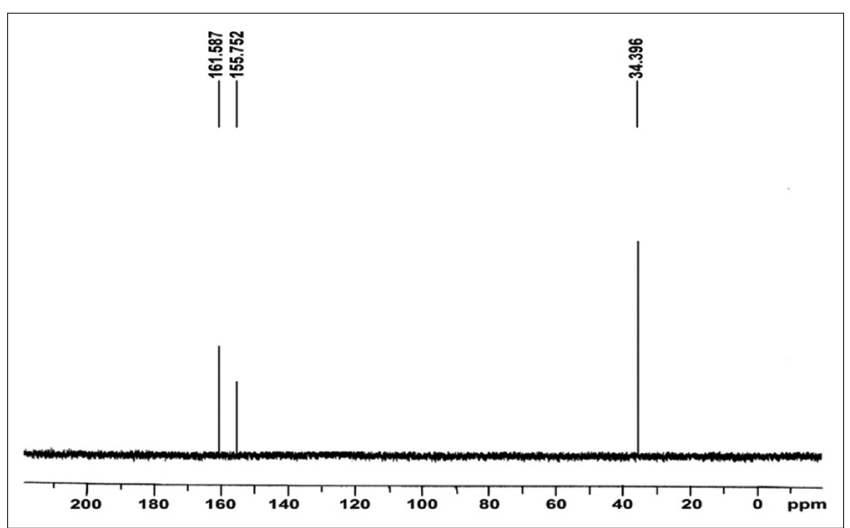

Fig. 12: The proton ${ }^{13} \mathrm{C}$ nuclear magnetic resonance of metformin

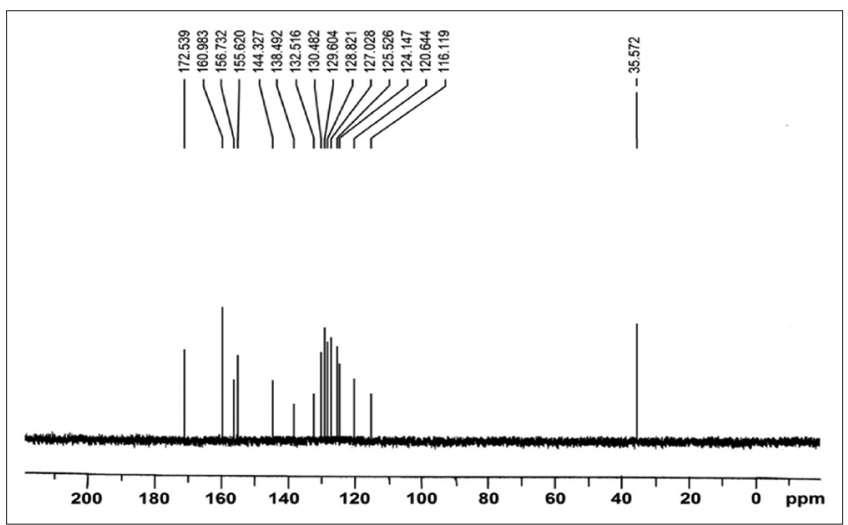

Fig. 13: The proton ${ }^{13} \mathrm{C}$ nuclear magnetic resonance of 3-hydroxyflavone and metformin ligand

decrease in the levels of hemoglobin and the levels were significantly reverted back to near reference range in mixed ligand zinc complex treated diabetic rats similar to that of metformin-treated group of rats.

The levels of plasma protein, blood urea, uric acid, and serum creatinine were depicted in Table 2. Diabetic rats showed decreased plasma protein level with concomitantly increased levels of renal tissue markers such as urea, uric acid, and creatinine. These levels were significantly reverted back to near normalcy in zinc mixed ligand complex treated diabetic rats. Metformin-treated diabetic rats also showed similar improvement in the levels of plasma protein, blood urea, uric acid, and serum creatinine. 
Table 1: The levels of fasting blood glucose, HbA1c, plasma insulin, C-peptide, and urine sugar in control and experimental groups of rats

\begin{tabular}{|c|c|c|c|c|c|c|}
\hline Groups & Blood glucose & $\mathrm{Hb}$ & HbA1c & Insulin & C-peptide & Urine sugar \\
\hline Control & $93.11 \pm 4.57$ & $13.23 \pm 0.10$ & $5.02 \pm 0.24$ & $15.37 \pm 0.17$ & $0.24 \pm 0.02$ & Nil \\
\hline Diabetic control & $310.28 \pm 11.27^{\mathrm{a} *}$ & $9.38 \pm 0.07^{2} *$ & $12.55 \pm 0.47^{* a}$ & $9.97 \pm 0.15^{\mathrm{a} *}$ & $0.11 \pm 0.01^{\mathrm{a} *}$ & +++ \\
\hline Diabetic+Zn-3HF-metformin & $120.59 \pm 7.16^{\mathrm{b} *}$ & $12.05 \pm 0.08^{\mathrm{b} *}$ & $7.11 \pm 0.22^{b *}$ & $13.71 \pm 0.07^{\mathrm{b} * *}$ & $0.18 \pm 0.03^{\mathrm{b} *}$ & Nil \\
\hline Diabetic+metformin & $119.9 \pm 7.09^{\mathrm{b} *}$ & $12.87 \pm 0.07^{\mathrm{b} *}$ & $6.68 \pm 0.13^{\mathrm{b} *}$ & $14.07 \pm 0.05^{\mathrm{b} *}$ & $0.19 \pm 0.03^{\mathrm{b} *}$ & Nil \\
\hline
\end{tabular}

Units are expressed as $\mathrm{mg} / \mathrm{dL}$ for blood glucose, \% for hemoglobin, $\%$ hemoglobin for HbA1c, $\mu \mathrm{U} / \mathrm{mL}$ for plasma insulin and pmol/mL for plasma C-peptide; +++ indicates more than $2 \%$ sugar. Results are expressed as mean \pm SEM $(n=6)$. One-way ANOVA followed by post hoc test LSD was done. Values are statistically significant at ${ }^{*} \mathrm{p}<0.05$. The results were ${ }^{\mathrm{a}}$ compared to control rats and ${ }^{\mathrm{b}}$ compared to diabetic rats. SEM: Standard error of the mean, LSD: Least significant difference, HbA1c: Glycosylated hemoglobin

Table 2: Effect of Zn-3HF-metformin complex on plasma protein and blood urea and serum creatinine levels in an experimental group of rats after 30-day treatment

\begin{tabular}{|c|c|c|c|c|}
\hline Groups & Plasma protein & Blood urea & Uric acid & Serum creatinine \\
\hline Control & $8.62 \pm 0.11$ & $24.61 \pm 0.61$ & $2.32 \pm 0.09$ & $0.46 \pm 0.01$ \\
\hline Diabetic control & $6.01 \pm 0.10^{\mathrm{a} *}$ & $46.18 \pm 0.95^{\mathrm{a} *}$ & $6.28 \pm 0.21^{\mathrm{a} *}$ & $1.10 \pm 0.02^{\mathrm{a} *}$ \\
\hline Diabetic+Zn-3HF-metformin & $7.12 \pm 0.12^{\mathrm{b} *}$ & $26.08 \pm 0.69^{\mathrm{b} *}$ & $2.83 \pm 0.15^{\mathrm{b} *}$ & $0.56 \pm 0.01^{\mathrm{b} *}$ \\
\hline Diabetic+metformin & $7.82 \pm 0.12^{\mathrm{b} *}$ & $23.63 \pm 0.98^{\mathrm{b} *}$ & $2.46 \pm 0.11^{\mathrm{b} *}$ & $0.48 \pm 0.01^{\mathrm{b} *}$ \\
\hline
\end{tabular}

Units are expressed as $\mathrm{g} / \mathrm{dL}$ for plasma protein, $\mathrm{mg} / \mathrm{dL}$ for blood urea, uric acid and serum creatinine. Values are given as mean \pm SEM for groups of six rats in each. One-way ANOVA followed by post hoc test LSD was done. Values are statistically significant at ${ }^{ } \mathrm{p}<0.05$. The results were ${ }^{\mathrm{a}} \mathrm{compared}$ to control rats and ${ }^{\mathrm{b}} \mathrm{compared}$ to diabetic rats. SEM: Standard error of the mean, LSD: Least significant difference

Table 3: Effect of Zn-3HF-metformin complex on levels of activities of AST, ALT, and ALP in the serum of experimental group of rats

\begin{tabular}{lll}
\hline Groups & AST & ALT \\
\hline Control & $71.80 \pm 2.12$ & $20.48 \pm 0.55$ \\
Diabetic control & $131.02 \pm 2.32^{\mathrm{a} *}$ & $44.95 \pm 1.62^{\mathrm{a} *}$ \\
Diabetic+Zn- 3HF-metformin & $74.57 \pm 0.76^{\mathrm{b} *}$ & $18.89 \pm 0.75^{\mathrm{b} *}$ \\
Diabetic+metformin & $72.54 \pm 0.21^{\mathrm{b} *}$ & $21.13 \pm 0.30^{\mathrm{b} *}$ \\
\hline
\end{tabular}

Enzyme activities are expressed as AST and ALT -1 moles of pyruvate liberated/h/mg of protein, ALP - 1 moles of phenol liberated/min/mg of protein. Results are expressed as mean \pm SEM $[n=6]$. One-way ANOVA followed by post hoc test LSD was done. Values are statistically significant at * $<<0.05$. The results were ${ }^{a}$ compared to control rats and ${ }^{\mathrm{b}}$ compared to diabetic rats. SEM: Standard error of the mean, LSD: Least significant difference, ALP: Alkaline phosphatase, AST: Aspartate aminotransferase, ALT: Alanine aminotransferase

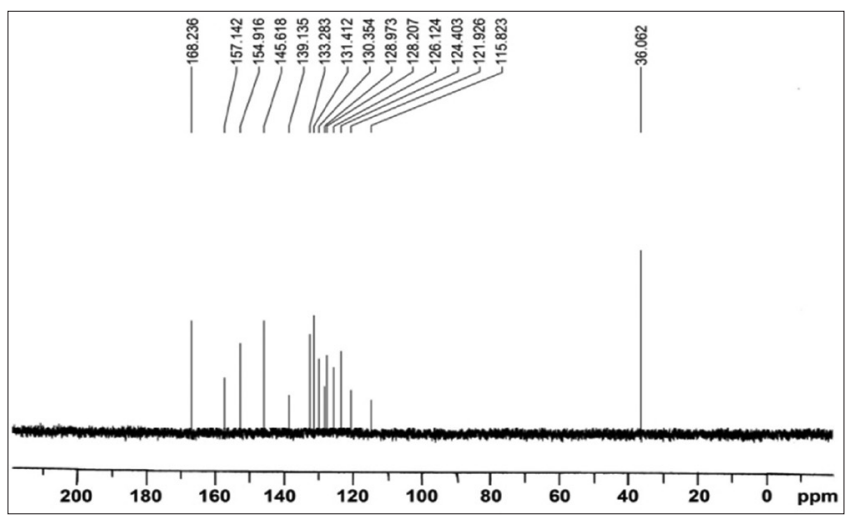

Fig. 14: The proton ${ }^{13} \mathrm{C}$ nuclear magnetic resonance of $\mathrm{Zn}$-Schiff base ligand

The activities of pathophysiological enzymes such as AST, ALT, and ALP were presented in Table 3. Diabetic control rats showed elevated activities of these enzymes when compared with control rats. The elevated activities of these hepatic marker enzymes in diabetic rats were significantly reduced on treatment with the mixed ligand zinc complex.

\section{DISCUSSION}

When lifestyle interventions such as diet control and exercise are not feasible to manage normoglycemia in patients with DM, pharmacological therapy is inevitable to prevent the consequences of chronic hyperglycemia. In general, the choice of any drug for the treatment of diabetes must balance the glucose lowering ability, chronic side effects and the anticipation of additional health benefits, cost and other practical aspects of patients care such as dosing schedule. New chemical entities from natural sources have been explored for safer antidiabetic agents as they elicit relatively fewer side effects. Likewise, if the therapeutic dose of an oral hypoglycemic drug (OHD) could be partly reduced by replacing it with a biologically active phytochemical, the side effects caused by the former could be reduced to a greater extent [20]. However, the interactions between the OHD and the phytochemical in terms of stability, bioavailability, and metabolism have to be established for successful therapeutic strategies [21].

The addition of metformin to insulin therapy in T1DM is associated with reductions in insulin dose requirement and HbA1c levels [22]. However, the combination of metformin with rosiglitazone or gliflozins (selective inhibitors of sodium-glucose co-transporter-2) or acarbose ( $\alpha$-glucosidase inhibitor) or GLP-1 (DPP-IV inhibitor) failed to decline IR in T2DM $[23,24]$. Although a large number of scientific literature support the use of metformin as a unique drug for the treatment of T2DM, contraindications such as lactic acidosis and gastrointestinal tract complications are frequently reported with higher doses of metformin treatment [25].

The structure of metformin and its metal complexes in solution is $\mathrm{pH}$ dependent because of the strong basic character of the guanidine moiety present in metformin. Metformin exists in several forms depending on the $\mathrm{pH}$. It exists in the diprotonated $\left(\mathrm{H}_{2} \mathrm{MET}\right)^{2+}$ form in strong acidic medium and the monoprotonated ( $\mathrm{H} \mathrm{MET}^{+}$form in weak medium. However, metformin is neutral as well as deprotonated (MET)- in the strong alkaline medium [26].

Previous reports on the progression of new zinc complexes revealed that the zinc complex formation with suitable ligands may afford proper lipophilicity which is considered as a prerequisite for efficient 


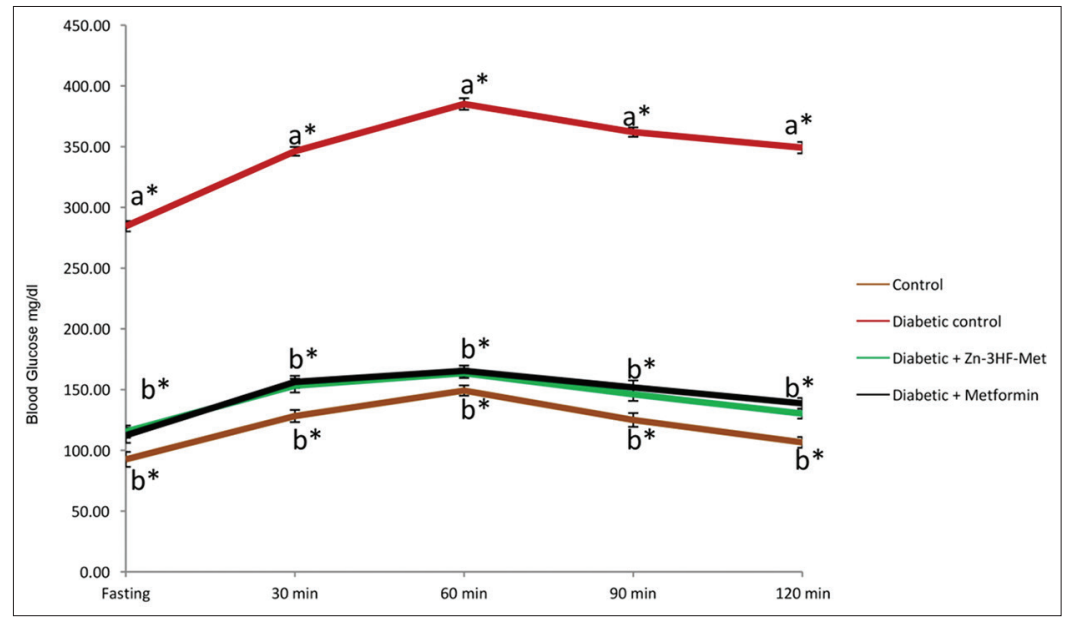

Fig. 15: Effect of zinc mixed ligand complex on oral glucose load test in experimental Type 2 diabetic rats. Results are expressed as a mean \pm standard error of the mean $(n=6)$. One-way ANOVA followed by post hoc test least significant difference was done. Values are statistically significant at ${ }^{*} p<0.05$. The results were ${ }^{a}$ compared to control rats and ${ }^{\mathrm{b}}$ compared to diabetic rats.

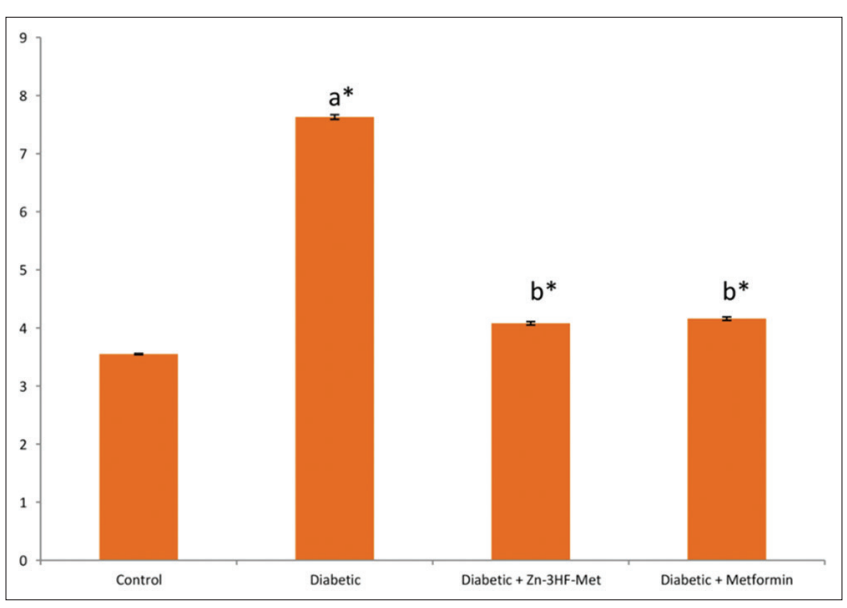

Fig. 16: Homeostasis model assessment of insulin resistance in control and experimental groups of rats. Results are expressed as a mean \pm standard error of the mean $(n=6)$. One-way ANOVA followed by post hoc test least significant difference was done. Values are statistically significant at $* \mathbf{p}<0.05$. The results were ${ }^{\mathrm{a}}$ compared to control rats and ${ }^{\mathrm{b}}$ compared to diabetic rats

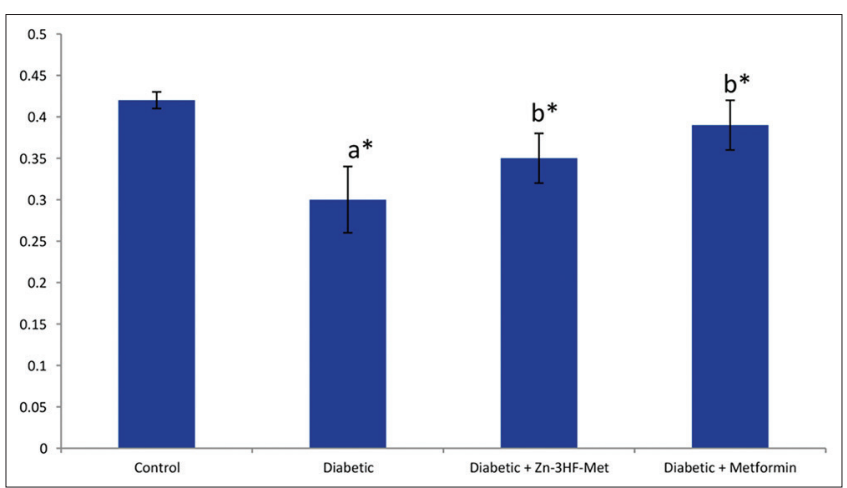

Fig. 17: QUICK-I index in control and experimental groups of rats. Results are expressed as a mean \pm standard error of the mean ( $n=6$ ). One-way ANOVA followed by post hoc test least significant difference was done. Values are statistically significant at ${ }^{*} \mathbf{p}<0.05$.

The results were ${ }^{\mathrm{a}}$ compared to control rats and $\mathrm{d}^{\mathrm{b}}$ compared to diabetic rats

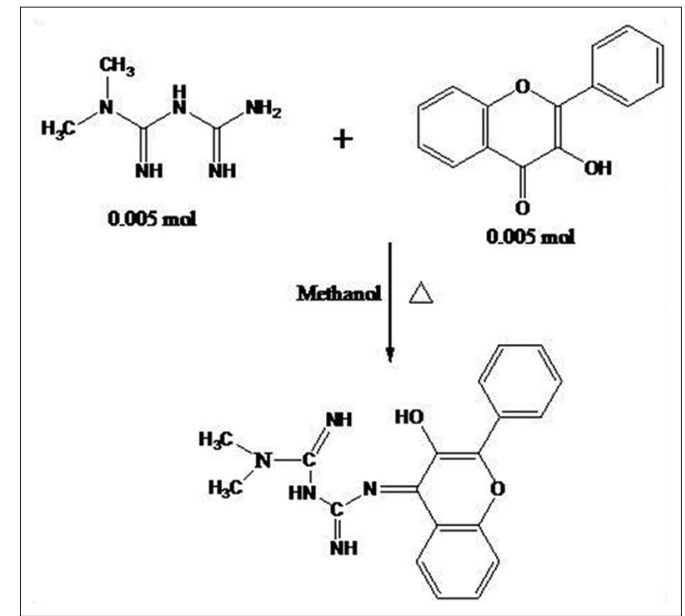

Scheme 1: Structure of 3-hydroxyflavone and metformin Schiff base ligand

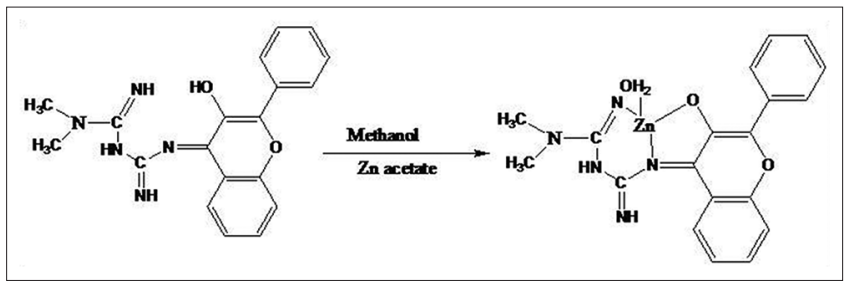

Scheme 2: Structure of zinc-Schiff base ligand

penetration through the biomembranes. This, in turn, results in an improved gastrointestinal absorption function when compared to their inorganic forms [27]. To improve the bioavailability, intestinal absorption and reduce the chronic toxicity of zinc, in the present study, metformin and 3-hydroxyflavone were used as a ligand (L) to synthesize a new zinc complex.

In free metformin, the free amino acid exhibit versus $\left(\mathrm{NH}_{2}\right)$ around $3100 / \mathrm{cm}$. The bands in the region of $3372 / \mathrm{cm}$ and $3289 / \mathrm{cm}$ denote the presence of $\mathrm{N}-\mathrm{H}$ stretching. The sharp peaks around $2800 / \mathrm{cm}$ indicate the presence of methyl groups coordinated to nitrogen group and the nitrogen-linked with carbon and hydrogen. The peak around $1150 / \mathrm{cm}$ arises due to the presence of carbon-nitrogen stretching. 
Likewise, metformin- free-3-hydroxyflavone (Schiff base) has shown several peaks. In free 3-hydroxyflavone, the peak around 3200/cm indicates the presence of the hydroxyl group in the aromatic ring. Likewise, the peak around $3050 / \mathrm{cm}$ confirms the presence of $\mathrm{C}-\mathrm{H}$ stretching. The additional peaks in the region of 1650 and $v 1587 / \mathrm{cm}$ are due to the existence of carbonyl and $\mathrm{C}=\mathrm{C}$ groups. The peaks found in the range of $1350-1255 / \mathrm{cm}$ correspond to C-O and C-O-C in the Schiff base.

Mixed ligand complex exhibit the characteristic bands of the involved ligands, namely, metformin and 3-hydroxyflavone. The band in the region of $3100 / \mathrm{cm}$ corresponding to the amine group shifted to the lower frequency region $3050(v=50 / \mathrm{cm})$ in the spectrum of the Ligand, indicating the involvement of the amino nitrogen in the coordination. The shift in the region of carbonyl group from 1650 to 1638 also confirms the formation of imine group. The IR spectra provide valuable information regarding the nature of functional groups attached to the zinc atom. The Schiff base exhibit a characteristic strong band around $1638 / \mathrm{cm}$ due to the $v(\mathrm{C}=\mathrm{N})$. This band is shifted to lower wave number $1617 / \mathrm{cm}$ in complex, indicating coordination of azomethine nitrogen atom of the Schiff base [28].

A broadband in the range of $3448 / \mathrm{cm}$, due to phenolic $-\mathrm{OH}$ group of Schiff base, disappeared in the zinc (II) complex confirming the participation of oxygen of phenolic group in coordination with the metal ion. This is further confirmed by the shift in the $v(\mathrm{C}-0)$ band from $1242 / \mathrm{cm}$ to a lower frequency to the extent of $1235 / \mathrm{cm}$ in respective $\mathrm{Zn}$ (II) complex [29]. The spectra of the metal complex showed new bands in the regions 540 and $460 / \mathrm{cm}$ assigned to $v(\mathrm{M}-0)$ and $v(\mathrm{M}-\mathrm{N})$, respectively [30]. The sharp bands appeared in the spectrum of the ligand in the region of $\sim 3200$ and $\sim 1510 / \mathrm{cm}$ were due to $\mathrm{N}-\mathrm{H}$ stretching frequency. The medium intensity band appearing in the $2830-2950 / \mathrm{cm}$ region corresponds to aliphatic $v(\mathrm{C}-\mathrm{H})$, while aromatic $v(\mathrm{C}-\mathrm{H})$ stretches appear in the $3000-3100 / \mathrm{cm}$. There was no change in the position of $\mathrm{N}-\mathrm{H}$ stretching band of metformin, which confirms the nonparticipation of -NH group in coordination.

The molecular weight of the synthesized Schiff base ligand $\mathrm{C}_{19} \mathrm{H}_{19} \mathrm{~N}_{5} \mathrm{O}_{2}$ was confirmed by the presence of a molecular ion peak $[\mathrm{M}+]$ at $\mathrm{m} /$ $\mathrm{z}=349$. The other peaks at $\mathrm{m} / \mathrm{z}=273,245,195,167$, and 125 matches to the various fragments of $\mathrm{C}_{13} \mathrm{H}_{15} \mathrm{~N}_{2} \mathrm{O}_{2}, \mathrm{C}_{11} \mathrm{H}_{11} \mathrm{~N}_{5} \mathrm{O}_{2}, \mathrm{C}_{7} \mathrm{H}_{9} \mathrm{~N}_{5} \mathrm{O}_{2}, \mathrm{C}_{7} \mathrm{H}_{9} \mathrm{~N}_{3} \mathrm{O}_{2}$, and $\mathrm{C}_{6} \mathrm{H}_{7} \mathrm{NO}_{2}$, respectively. Thus, the mass spectral analysis confirms the molecular structure of the synthesized ligand. The molecular ion peak $[\mathrm{M}+]$ at $\mathrm{m} / \mathrm{z}=430$ confirm the molecular weight of the Schiff base $\mathrm{Zn}$ (II) complex $\mathrm{C}_{19} \mathrm{H}_{19} \mathrm{~N}_{5} \mathrm{O}_{3} \mathrm{Zn}$. The peaks at $\mathrm{m} / \mathrm{z}=412,336,308,258$, and 230 correspond to the various fragments $\mathrm{C}_{19} \mathrm{H}_{17} \mathrm{~N}_{5} \mathrm{O}_{2} \mathrm{Zn}, \mathrm{C}_{13} \mathrm{H}_{13} \mathrm{~N}_{5} \mathrm{O} 2 \mathrm{Zn}$, $\mathrm{C}_{11} \mathrm{H}_{9} \mathrm{~N}_{5} \mathrm{O}_{2} \mathrm{Zn}, \mathrm{C}_{7} \mathrm{H}_{7} \mathrm{~N}_{5} \mathrm{O}_{2} \mathrm{Zn}$, and $\mathrm{C}_{7} \mathrm{H}_{7} \mathrm{~N}_{3} \mathrm{O}_{2} \mathrm{Zn}$, respectively.

The ${ }^{1} \mathrm{H}$ NMR spectral studies on the ligand were recorded in DMSO-d6. In the NMR spectrum of the ligand L, the signal as a singlet in the range $\delta 1.82 \mathrm{ppm}$ indicates the presence of six methyl protons in the metformin molecule. A few doublets and in few cases some overlapping doublets/multiplets are observed in the aromatic region ranges from $\delta 7.3$ to $8.5 \mathrm{ppm}$. The phenolic proton was observed at $\delta 9.35 \mathrm{ppm}$ as a singlet. The additional singlets in the region of $\delta 6.9$ and $7.2 \mathrm{ppm}$ confirm the presence of two amides $(\mathrm{C}=\mathrm{NH})$ and one $\mathrm{C}-\mathrm{NH}$ in the ligand.

The aromatic protons of the synthesized zinc complex were visualized around $\delta 7.3-8.5 \mathrm{ppm}$, respectively, and the signal corresponding to the two amide groups around $\delta 6.9 \mathrm{ppm}$ is notably shifted to $\delta 6.8 \mathrm{ppm}$ corresponding to one proton. Moreover, the absence of the singlet in the region of $\delta 9.35 \mathrm{ppm}$ due to the presence of phenolic proton and the presence of new one showed a characteristic new peak centered between $\delta 4.79 \mathrm{ppm}$, which confirms the presence of coordinated water molecules in the complex [31].

The ${ }^{13} \mathrm{C}$ NMR spectrum of the Schiff base showed signals in the region of $\delta 116-155 \mathrm{ppm}$ indicating the presence of aromatic carbons. The peak in the region of $\delta 172 \mathrm{ppm}$ indicates the presence of $\mathrm{C}=\mathrm{N}$ carbon. The methylene carbons have appeared in the region of $\delta 35 \mathrm{ppm}$. Likewise, the amide carbons were noticed in the region of $\delta 156$ and $160 \mathrm{ppm}$. In the ${ }^{13} \mathrm{C}$ NMR spectrum of zinc complex, the peaks around $\delta 115-154 \mathrm{ppm}$ were due to the presence of aromatic carbons. From the spectrum, we can notice that there are appreciable decrease and absence of peaks in the region of $\delta 168$ and $160 \mathrm{ppm}$, which was due to the imine and amide carbons. This suggests the formation of coordination bond between imine and amide nitrogen. From the spectral data obtained, it can be concluded that except imine and amide carbons all other carbon signals did not show any notable shifts.

Based on the results obtained through the dose-dependent study of mixed ligand-zinc complex on the levels of fasting blood glucose, $10 \mathrm{mg} / \mathrm{kg}$ b.w/rat/day for 30 days was fixed as the optimal dosage for assessing the antidiabetic properties of the newly synthesized zinc mixed ligand complex. HFD fed induced resistance low-dose STZinduced experimental T2D in rats is an ideal animal model as it closely resembles the clinical and metabolic characteristics of human T2D and widely used for pharmacological screening [32].

The maintenance of normal glucose homeostasis involves the simultaneous and coordinated roles of the pancreatic $\beta$-cells, the liver and the peripheral tissues primarily skeletal muscle [33]. OGTT is the widely used biochemical assay to evaluate the glucose tolerance in vivo. However, it is difficult to derive consequential information about wholebody, peripheral tissue or hepatic sensitivity to insulin from the results of the OGTT [34]. Due to peripheral IR, the blood glucose concentration before oral glucose load in the diabetic rats was significantly higher than the glucose levels in control rats.

Due to peripheral IR, diabetic rats showed a significant elevation of HOMA-IR and QUICKI values that were decreased to physiological range on treatment with oral administration of mixed ligand zinc complex as well as metformin indicating that the mixed ligand zinc complex improves insulin sensitivity in diabetic rats. Due to the insulin insufficiency in diabetic rats, the fasting blood glucose levels were elevated, which ultimately leads to elevated HbA1c levels, because hemoglobin in circulation binds to glucose by irreversible, non-enzymatic manner to form HbA1c [35]. The level of HbA1c reflects the average blood glucose level over the past 3 months. Thus, HbA1c levels serve as a golden marker for the diagnosis as well as prognosis of DM [36].

Plasma insulin and C-peptide levels in the diabetic rats were markedly reduced when compared with control rats whereas these altered levels were significantly improved to physiological range in diabetic rats treated with mixed ligand zinc complex. In the absence of systemic treatment, chronic hyperglycemia in diabetic condition causes increased insulin secretion from the functioning pancreatic $\beta$ cells, ultimately leads to hyperinsulinemia coupled with hyperglycemia. This condition stresses the pancreatic $\beta$ cells to produce more insulin, which resulted in the severe destruction of $\beta$ cells and responsible for decreased secretion of insulin in diabetic rats [37]. Subsequently, decreased insulin secretion from functioning pancreatic $\beta$ cells causes a reduced level of C-peptide or connecting peptide. C-peptide was secreted in equimolar concentrations of insulin. Urine sugar which was present in diabetic rats was no longer detected; suggesting zinc complex enhances glucose homeostasis in diabetic rats. The efficacy of the mixed ligand complex in ameliorating the hyperglycemia was comparable with diabetic rats treated with metformin which was administered at a concentration of $50 \mathrm{mg} / \mathrm{kg}$ b.w.

Enhanced IR coupled with increased muscle wasting is responsible for the observed increase in protein glycation and reduced protein synthesis which resulted in decreased plasma protein level in diabetic condition [38]. Decreased protein anabolism with concomitantly increased protein catabolism causes remarkable effects in the metabolic functions of renal tissues, which leads to elevated levels of blood urea, serum uric acid, and serum creatinine. Protein catabolic end products, namely, urea, creatine, and phosphocreatine breakdown product creatinine, which are considered as energy storage compounds in muscle 
tissues. The levels of these markers were significantly reduced in zinc mixed ligand complex treated diabetic rats, indicating the beneficial effect of the complex in ameliorating diabetes-associated renal complications.

Measurement of activity of these pathophysiological enzymes is one of the most sensitive and dramatic indicators of hepatocyte injury. Similarly, the cytosolic enzyme ALP is released into the circulation during cellular damage [39]. During tissue injury, the soluble enzymes ALT and AST are released into portal circulation, and the significantly elevated activities of these enzymes were indicative of cellular damage and loss of the functional integrity of the cell membranes. This data evidenced the non-toxic as well as tissue protective nature of the mixed ligand zinc complex. More recently, we have reported the antidiabetic properties of a newly synthesized metformin-3-hydroxyflavone complex in HFD fed low-dose STZ-induced experimental T2D in rats $[40,41]$. However, the results of the present study clearly established that the zinc mixed ligand complex shows better antidiabetic properties relatively at a lesser concentration indicating that the addition of zinc significantly improved the efficacy of metformin-3-hydroxyflavone (Schiff base) without any toxicity.

The data obtained through OGTT, HOMA-IR, and QUICKI and the estimation of important biochemical parameters evidenced that the oral administration of zinc mixed ligand complex significantly improves the insulin sensitivity in diabetic rats to maintain normoglycemia. Altered protein metabolism was normalized on treatment with zinc mixed ligand complex, which suggests that the complex exerts beneficial effects on renal functions. The assay of cytosolic as well as membrane-bound enzymes indicates the non-toxic as well as tissue protective nature of zinc mixed ligand complex. Further studies are in progress to understand the molecular mechanisms involved in the action of zinc mixed ligand complex in ameliorating the primary and secondary complications of T2DM.

\section{ACKNOWLEDGMENT}

The research fellowship awarded by the University Grants Commission, Government of India, to Mr. K. Muruganantham (GCCO/A-2/UGCMERITORIOUS/2015/1552 dated $19^{\text {th }}$ November 2015) is gratefully acknowledged.

\section{CONFLICTS OF INTERESTS}

The authors acknowledge that they have no declaration of interest to declare.

\section{REFERENCES}

1. American Diabetes Association. Diagnosis and classification of diabetes mellitus. Diabetes Care 2010;33 Suppl 1:S62-9.

2. International Diabetes Federation. IDF Diabetes Atlas. $7^{\text {th }}$ ed. Brussels, Belgium: International Diabetes Federation; 2015.

3. Tabish SA. Is diabetes becoming the biggest epidemic of the twentyfirst century? Int J Health Sci (Qassim) 2007;1:V-VIII.

4. Thulé PM. Mechanisms of current therapies for diabetes mellitus Type 2. Adv Physiol Educ 2012;36:275-83.

5. Redmon B, Caccamo D, Flavin P, Michels R, O'Connor P, Roberts J, et al. Diagnosis and Management of Type 2 Diabetes Mellitus in Adults. Bloomington (MN): Institute for Clinical Systems Improvement (ICSI); 2014. p. 85.

6. Ramakrishna A, Ravishankar GA. Influence of abiotic stress signals on secondary metabolites in plants. Plant Signal Behav 2011;6:1720-31.

7. Pandey A, Tripathi P, Pandey R, Srivatava R, Goswami S. Alternative therapies useful in the management of diabetes: A systematic review. J Pharm Bioall Sci 2011:3:504-12.

8. Cornard JP, Merlin JC. Comparison of the chelating power of hydroxyflavones. J Mol Struct 2003;651-653:381-7.

9. Rice-Evans CA, Miller NJ, Paganga G. Structure-antioxidant activity relationships of flavonoids and phenolic acids. Free Radic Biol Med 1996;20:933-56.

10. Witters LA. The blooming of the French lilac. J Clin Invest 2001;108:1105-7.

11. Maruthur NM, Tseng E, Hutfless S, Wilson LM, Suarez-Cuervo C,
Berger Z, et al. Diabetes medications as monotherapy or metforminbased combination therapy for Type 2 diabetes: A systematic review and meta-analysis. Ann Intern Med 2016;164:740-51.

12. Quaile MP, Melich DH, Jordan HL, Nold JB, Chism JP, Polli JW, et al. Toxicity and toxicokinetics of metformin in rats. Toxicol Appl Pharmacol 2010;243:340-7.

13. Tsuji A, Sakurai H. Vanadyl ion suppresses nitric oxide production from peritoneal macrophages of streptozotocin-induced diabetic mice. Biochem Biophys Res Commun 1996;226:506-11.

14. Maanvizhi S, Boppana T, Krishnan C, Arumugam G. Metal complexes in the management of diabetes mellitus: A new therapeutic strategy. Int J Pharm Pharm Sci 2014;6:40-4.

15. Vijayaraghavan K, Iyyam Pillai S, Subramanian SP. Design, synthesis and characterization of zinc-3 hydroxy flavone, a novel zinc metallo complex for the treatment of experimental diabetes in rats. Eur J Pharmacol 2012;680:122-9.

16. Sendrayaperumal V, Iyyam Pillai S, Subramanian S. Design, synthesis and characterization of zinc-morin, a metal flavonol complex and evaluation of its antidiabetic potential in HFD-STZ induced Type 2 diabetes in rats. Chem Biol Interact 2014;219:9-17.

17. Maheswari JU, Pillai SI, Subramanian SP. Zinc-silibinin complex: Synthesis, spectral characterization and biochemical evaluation of antidiabetic potential in high fat fed low dose STZ induced Type 2 diabetic rats. J Chem Pharm Res 2015;7:2051-64.

18. Gopalakrishnan V, Pillai SI, Subramanian SP. Synthesis, spectral characterization and biochemical evaluation of antidiabetic properties of a new zinc-diosmin complex studied in high fat diet fed-low dose streptozotocin induced experimental Type 2 diabetes in rats. Biochem Res Int 2015;2015:350829.

19. Srinivasan K, Viswanad B, Asrat L, Kaul CL, Ramarao P. Combination of high-fat diet-fed and low-dose streptozotocin-treated rat: A model for type 2 diabetes and pharmacological screening. Pharmacol Res 2005;52:313-20.

20. Prabhakar PK, Doble M. Effect of natural products on commercial oral antidiabetic drugs in enhancing 2-deoxyglucose uptake by 3T3-L1 adipocytes. Ther Adv Endocrinol Metab 2011;2:103-14.

21. Panchal I, Sen DJ, Navle A, Shah U. Structure-based drug designing, scoring, and synthesis of some substituted sulphonylureas/guanidinebased derivatives as hypoglycemic agents. Int J Pharm Pharm Sci 2017;9:226-32.

22. Vella S, Buetow L, Royle P, Livingstone S, Colhoun HM, Petrie JR, et al. The use of metformin in Type 1 diabetes: A systematic review of efficacy. Diabetologia 2010;53:809-20.

23. Komoroski B, Vachharajani N, Feng Y, Li L, Kornhauser D, Pfister M, et al. Dapagliflozin, a novel, selective SGLT2 inhibitor, improved glycemic control over 2 weeks in patients with Type 2 diabetes mellitus. Clin Pharmacol Ther 2009;85:513-9.

24. Retnakaran R, Qi Y, Harris SB, Hanley AJ, Zinman B. Changes over time in glycemic control, insulin sensitivity, and beta-cell function in response to low-dose metformin and thiazolidinedione combination therapy in patients with impaired glucose tolerance. Diabetes Care 2011;34:1601-4.

25. Dujic T, Zhou K, Donnelly LA, Tavendale R, Palmer CN, Pearson $\mathrm{ER}$, et al. Association of organic cation transporter 1 with intolerance to metformin in Type 2 diabetes: A GoDARTS study. Diabetes 2015;64:1786-93.

26. Zhu M, Lu L, Yang P, Jinb X. Bis(1,1-dimethylbiguanido)nickel(II). Acta Crystallogr Sect 2002;58:272-4.

27. Enyedy EA, Hollender D, Kiss T. Lipophilicity of kinetically labile metal complexes through the example of antidiabetic $\mathrm{zn}(\mathrm{II})$ and VO(IV) compounds. J Pharm Biomed Anal 2011;54:1073-81.

28. Sobola AO, Watkins GM, Brecht BV. Synthesis, characterization and antimicrobial activity of copper(II) complexes of some orthosubstituted aniline schiff bases; Crystal structure of bis(2-methoxy-6imino)methylphenol copper(II) complex. Afr J Chem 2014;67:45-51.

29. Saydam S, Yilmaz E. Synthesis, characterization and thermal behavior of 4-chloromethyl-2-(2-hydroxybenzilidenehydrazino) thiazole and its complexes with cr(III), co(II), ni(II) and cu(II). Spectrochim Acta A Mol Biomol Spectrose 2006;63:506-10

30. Ferraro JR. Low-Frequency Vibrations of Inorganic and Coordination Compounds. New York: Plenum Press; 1971.

31. Tas E, Aslanoglu M, Guler M, Ulusoy M. Synthesis, characterization and electrochemical properties of copper(II) complexes with novel bidentate salicylaldimines derived from 3,5-DI-t-butyl-2hydroxybenzaldehyde. J Coord Chem 2004;57:583-9.

32. Reed MJ, Meszaros K, Entes LJ, Claypool MD, Pinkett JG, Gadbois TM, et al. A new rat model of Type 2 diabetes: The fat-fed, streptozotocin- 
treated rat. Metabolism 2000;49:1390-4.

33. Wilcox G. Insulin and insulin resistance. Clin Biochem Rev 2005;26:19- 39

34. Stumvoll M, Mitrakou A, Pimenta W, Jenssen T, Yki-Järvinen H, Van Haeften T, et al. Use of the oral glucose tolerance test to assess insulin release and insulin sensitivity. Diabetes Care 2000;23:295-301.

35. Clark SL, Santin AE, Bryant PA, Holman R, Rodnick KJ. The initial noncovalent binding of glucose to human hemoglobin in nonenzymatic glycation. Glycobiology 2013;23:1250-9.

36. Florkowski C. HbAlc as a diagnostic test for diabetes mellitusreviewing the evidence. Clin Biochem Rev 2013;34:75-83.

37. Wajchenberg BL. Beta-cell failure in diabetes and preservation by clinical treatment. Endocr Rev 2007;28:187-218.
38. Cerf ME. Beta cell dysfunction and insulin resistance. Front Endocrinol (Lausanne) 2013;4:37

39. Sallie R, Tredger JM, Williams R. Drugs and the liver. Part 1: Testing liver function. Biopharm Drug Dispos 1991;12:251-9.

40. Jaiganesh C, Devi VR, Pillai SI, Subramanian S. Synthesis, characterization And evaluation of antidiabetic properties of a new metformin-3-hydroxyflavone complex studied in high fat diet fed-low dose streptozotocin induced experimental Type 2 diabetes in wistar rats. Int J Pharm BioSci 2017;8:1-15.

41. Jaiganesh C, Subramanian S. Metformin-3-hydroxyflavone, a new schiff base complex modulates the activities of carbohydrate regulatory enzymes in high fat diet fed-low dose streptozotocin induced Type 2 diabetes in experimental rats. J Chem Pharm Res 2017;9:90-100. 